\title{
Ober das Vorkommen von Ammoniak in Keimpfianzen und aber seine Bildung bei der Autolyse solcher Pflanzen.
}

Von

\author{
N. Castoro.
}

(Aus dem agrikultur-chemischen Laboratorium des Polytechnikums in Zürich.)

(Der Redaktion zugegangen am 12. Januar 1907.)

Das Vorkommen von Ammoniak in Keimpflanzèn ist von E. Schulze und seinen Mitarbeitern mehrfach nachgewiesen worden; doch liegen quantitative Bestimmungen dieses Keimpflanzenbestandteiles nur in kleiner Anzahl vor. Es schien wünschenswert, diese Bestimmungen zu vermehren und zugleich zu prüfen, ab bei der Autolyse der Keimpflanzen Ammoniak sich bildet.

Ehe ich die bei meinen. Versuchen erhaltenen Resultate mitteile, muß ich zunächst über die dabei in Anwendung gekommenen Untersuchungsmethoden einiges sagen. Bekanntlich ist es nicht ganz leicht, den Ammoniakgehalt von Pflanzenextrakten in einwandsfreier Weise zu bestimmen. Die für diesen Zweck häufig verwendete Schlösingsche Methode liefert keine zuverlässigen Resultate, wenn in den Extrakten neben Ammoniak Amide, die in Berührung mit kalter Kalkmilch Ammoniak abspalten, enthalten sind. Es ist nun bekannt, daß zwei Amide von solchem Verhalten in den Pflanzen sehr verbreitet sind, nämlich das Asparagin und das Glutamin; möglich aber ist es, daß neben letzteren in den Pflanzen noch andere, bis jetzt nicht isolierte Stickstoffverbindungen vorkommen, die sich gegen Kalkmilch ebenso verhalten. Auch das Abdestillieren des Ammoniaks mit Magnesia bei gewöhnlichem Luftdruck ist keine Methode, die bei Gegenwart von Asparagin und Glutamin brauchbare Resultate liefert, da diese beiden Amide beim Kochen ihrer wässerigen Lösungen mit Magnesia sich langsam zersetzen (das Glutamin wird dabei schneller zersetzt als das Asparagin). Zur Beseitigung des störendén Einflusses dieser 
beiden Amide auf die Ammoniakbestimmung benutzte E. Bosshard $\left.{ }^{1}\right)$ die Fällbarkeit des Ammoniaks durch Phosphorwolframsäure; nach der von ihm gegebenen Vorschrift säuert man die von den Eiweißstoffen so vollständig wie möglich befreiten Pflanzenextrakte mit Salzsäure oder Schwefelsäure an, fügt sodann Phosphorwolframsäure im Überschuß $\mathrm{zu}$, trennt die dadurch hervorgebrachten Niederschläge durch Abfiltrieren und Auswaschen mit verdünnter Schwefelsäure von den Lösungen, unterwirft sie sodann der Destillation unter Zusatz von Wasser und Magnesia und fängt das dabei übergehende Ammoniak in titrierter Säure auf. Auch dieses Verfahren, mit dessen Hilfe E. Schulze und E. Bosshard ${ }^{2}$ ) u. a. den Ammoniakgehalt der Keimpflanzen von Cucurbita pepo bestimmten, kann, wie von den genannten Autoren selbst hervorgehoben worden ist, nicht für absolut einwandsfrei erklärt werden. Denn es liegt im Bereich der Möglichkeit, daß in die Phosphorwolframsäureniederschläge neben Ammoniak noch andere flüchtige Basen oder auch irgend welche, bisher noch nicht bekannte Stickstoffverbindungen, die beim Kochen mit Wasser und Magnesia Ammoniak abspalten, eingehen; auch ist es nicht unmöglich, daß das Asparagin und das Glutamin in der stark angesäuerten Flüssigkeit schon in der Kälte langsam Ammoniak abspalten. Der durch letzteren Umstand bedingte Fehler wird allerdings ganz unwesentlich sein, wenn man die durch die Phosphorwolframsäure erzeugten Niederschläge schon nach kurzem Stehen abfiltriert.

Später schlug A. Longi ${ }^{8}$ ) ein anderes Verfahren zur Bestimmung des Ammoniakgehaltes von Pflanzenextrakten und tierischen Flüssigkeiten vor. Nach der von ihm gegebenen Vorschrift treibt man das Ammoniak durch Erhitzen der Extrakte mit Magnesia auf ca. $40^{\circ}$ C. im luftleeren Raume aus und fängt es in titrierter Säure auf. Longi konstatierte, daß Asparagin und Harnstoff bei dieser Behandlung nicht angegriffen werden, oder doch nur unbestimmbare Ammoniakmengen ab-

1) Zeitschrift für analytische Chemie, 22. Jahrgang (1883), S. 329.

2) Journal für praktische Chemie, N. F., Bd. XXXII, S. 439.

9) Landwirtschaftliche Versuchsstationen, Bd. XXXII, S. 16. 
Über das Vorkommen von Ammoniak in Keimpflanzen usw. 527

geben, und zog daraus die Schlußfolgerung, daß nach diesem Verfahren das Ammoniak auch bei Gegenwart von Amiden, aus denen leicht Ammoniak abgespalten wird, bestimmt werden kann.

Es schien mir zweckmäßig, bei meinen Versuchen das Bosshardsche und das Longische Verfahren nebeneinander anzuwenden. Ich erwähne hier gleich, daß die zuerst genannte Methode in der Regel etwas höhere Resultate lieferte, als die letztere; doch waren die Unterschiede nur gering. Bei Ausführung des Bosshardschen Verfahrens befolgte ich die von diesem Autor gegebene Vorschrift; für die Bestimmung nach Longis Methode bediente ich mich eines auch für die Ammoniakbestimmung im Käse von $\mathrm{E}$. Winterstein und W. Bissegger ${ }^{1}$ ) benutzten Apparates.

Da bisher nicht bekannt war, wie das Glutamin beim Erhitzen seiner wässerigen Lösung mit Magnesia auf $40^{\circ} \mathrm{C}$. sich verhält, so habe ich darüber einige Versuche angestellt. Ich fand, daß bei der angegebenen Temperatur durch Magnesia aus dem Glutamin Ammoniak nicht abgespalten wird, es sei denn, daß man die Destillation bis zum Eintrocknen der Flüssigkeit fortsetzt; doch wurden auch in diesem Falle nur Ammoniakmengen gebildet, die außer Betracht gelassen werden konnten. Auch bei Gegenwart von Glutamin kann man also den Ammoniakgehalt von Pflanzenextrakten nach dem Verfahren von Longi bestimmen.

I. Der Ammoniakgehalt etiolierter Keimpflanzen.

Im folgenden teile ich zunächst die Resultate mit, die bei Bestimmung des Ammoniakgehaltes etiolierter Keimpflanzen sich ergaben. Diese Keimpflanzen waren in großen, mit reinem Sand gefüllten Zinkblechkästen bei einer Temperatur von durchschnittlich ca. $20^{\circ}$ C. gezogen worden. Sie wurden teils in frischem Zustand untersucht, teils vor der Untersuchung bei einer Temperatur von ca. $60^{\circ}$ getrocknet.

Über die Einzelheiten des Versuchsverfahrens sind noch folgende Angaben zu machen: a) von den lufttrockenen, auf das feinste zerriebenen Keimpflanzen wurden je $10 \mathrm{~g}$ zur

1) Diese Zeitschrift, Bd. XLVII, S. 28. 
Extraktion des Ammoniaks entweder 14 Stunden lang mit kaltem, destilliertem Wasser oder eine kürzere Zeit mit warmem Wasser behandelt. Der Auszug wurde mit etwas reiner Gerbsäure, hierauf mit einigen Tropfen Bleiessig versetzt und auf ein bestimmtes Volumen (meistens $200 \mathrm{ccm}$ ) gebracht; dann wurde filtriert. Vom Filtrat wurden je $90 \mathrm{ccm}$ für die verschiedenen Versuche verwendet. Bei Anwendung des Bosshardschen Verfahrens wurde die Flüssigkeit mit Schwefelsäure stark angesäuert, dann mit Phosphorwolframsäure im Überschuß versetzt; der durch dieses Reagens hervorgebrachte Niederschlag wurde nach einstündigem Stehen abfiltriert, mit $5 \%$ iger Schwefelsäure ausgewaschen und schließlich der Destillation mit reiner Magnesia unterworfen (während der Destillation wurde ammoniakfreie Luft in den Destillierkolben eingeleitet). Bei Anwendung der Longischen Methode wurden $90 \mathrm{ccm}$ jenes Extraktes mit reiner Magnesia bei $40^{\circ} \mathrm{C}$. unter Luftverdünnung destilliert. ${ }^{1}$ ) Die Flüssigkeit wurde in diesem Falle fast vollständig abdestilliert, was eine Zeit von 4-5 Stunden beanspruchte. In beiden Fällen wurde die verdünnte Säure, in welcher das übergehende Ammoniak aufgefangen wurde, mit sehr verdünnter Natronlauge zurücktitriert. b) Falls frische Keimpflanzen für die Bestimmungen in Anwendung kamen, so wurde ein abgewogenes Quantum derselben, meistens $150 \mathrm{~g}$, im Mörser zerrieben, dann nach Zusatz von etwas Wasser bis zum Koagulieren der Eiweißstoffe erhitzt; die vom Ungelösten durch Abfiltrieren auf einem Seihtuch und Nachwaschen mit Wasser getrennte Flüssigkeit brachte ich nach Zusatz von etwas Gerbsäure und etwas Bleiessig auf ein bestimmtes Volumen; dann wurde filtriert. Abgemessene Anteile des Filtrats verwendete ich für die einzelnen Bestimmungen, deren Ausführung in der unter a) angegebenen Weise geschah.

In der nachfolgenden Tabelle habe ich die bei diesen Versuchen erhaltenen Resultate zusammengestellt:

1) Ich bediente mich dabei eines Apparates, wie ihn auch E. Winterstein und W. Bisegger (Diese Zeitschrift, Bd. XLIX) zur Bestimmung des Ammoniaks im Käse benutzt haben. 
Über das Vorkommen von Ammoniak in Keimpflanzen usw. $\mathbf{5 2 9}$

\begin{tabular}{|c|c|c|c|c|c|c|}
\hline & \multirow{2}{*}{$\begin{array}{c}\text { Alter } \\
\text { der } \\
\text { Keim- } \\
\text { pflanzen }\end{array}$} & \multicolumn{4}{|c|}{$\begin{array}{c}\text { g Ammoniakstickstoff in } 100 \mathrm{~g} \text { Pflanzen- } \\
\text { trockensubstanz }\end{array}$} \\
\hline & & & \multicolumn{2}{|c|}{$\begin{array}{c}\text { Bestimmt nach dem } \\
\text { Verfahren } \\
\text { von Bosshard }\end{array}$} & \multicolumn{2}{|c|}{$\begin{array}{c}\text { Bestimmt nach dem } \\
\text { Verfahren } \\
\text { von Longi }\end{array}$} \\
\hline \multirow{3}{*}{$\begin{array}{l}\text { Ge- } \\
\text { trcknete }\end{array}$} & $\begin{array}{l}\text { Lupinus } \\
\text { albus }\end{array}$ & $3-4$ Tage & $\begin{array}{l}0,0741 \\
0,0725\end{array}$ & Mittel 0,0733 & $\begin{array}{l}0,0725 \\
0,0678\end{array}$ & Mittel $0,07.02$ \\
\hline & $\begin{array}{l}\text { Lupinus } \\
\text { luteus }\end{array}$ & $3-4$ Tage & 0,0761 & - & $\begin{array}{l}0,0730 \\
0,0710\end{array}$ & Mittel 0,0720 \\
\hline & $\begin{array}{l}\text { Lupinus } \\
\text { albus }\end{array}$ & 7 Tage & - & - & $\begin{array}{l}0,0747 \\
0,0776\end{array}$ & Mittel 0,0762 \\
\hline panzen & $\begin{array}{l}\text { Lupinus } \\
\text { albus }\end{array}$ & $\begin{array}{c}11-12 \\
\text { Tage }\end{array}$ & - & - & $\begin{array}{l}0,1310 \\
0,1000\end{array}$ & Mittel 0,1155 \\
\hline \multirow{2}{*}{ von } & $\begin{array}{l}\text { Lupinus } \\
\text { albus }\end{array}$ & 20 Tage & - & - & $\begin{array}{l}0,1056 \\
0,1159\end{array}$ & Mittel 0,1108 \\
\hline & $\begin{array}{c}\text { Pisum } \\
\text { sativum }\end{array}$ & 12 Tage & - & - & $\begin{array}{l}0,1135 \\
0,1108\end{array}$ & Mittel 0,1122 \\
\hline \multirow{2}{*}{$\begin{array}{l}\text { Fische } \\
\text { jeim- } \\
\text { panzen } \\
\text { von }\end{array}$} & $\begin{array}{l}\text { Lupinus } \\
\text { albus }\end{array}$ & $\begin{array}{l}9-10 \\
\text { Tage }\end{array}$ & $\begin{array}{l}0,0763 \\
0,0773\end{array}$ & Mittel 0,0771 & - & - \\
\hline & $\begin{array}{c}\text { Cucurbita } \\
\text { Pepo }\end{array}$ & 7 Tage & $\begin{array}{l}0,1051 \\
0,1022\end{array}$ & Mittel 0,1034 & - & $\div$ \\
\hline
\end{tabular}

Aus den Zahlen der Tabelle ist zunächst zu ersehen, daß di nach der Bosshardschen Methode erhaltenen Zahlen etwas hảer liegen, als diejenigen, welche für die gleichen Substanzen neh dem Verfahren von Longi gefunden wurden; doch sind di Differenzen nicht bedeutend (sie betragen nur $0,003-0,004 \mathrm{~g}$ py $100 \mathrm{~g}$ Pflanzentrockensubstanz). Ferner zeigt die Tabelle, da der Ammoniakgehalt der untersuchten Keimpflanzen nur geing war; die Menge des Ammoniakstickstoffs betrug in maximo nr 0,1310 g pro 100 g Pflanzentrockensubstanz.

Wie aus den über das Versuchsverfahren oben gemachten Mteilungen hervorgeht, habe ich nur das in den wässerigen Etrakten erhaltene Ammoniak bestimmt. Hin und wieder wird agegeben, daß auch der in Wasser unlösliche Teil der Pflanzen Aumoniak enthält, und zwar in Form von Ammoniummagnesium- 
phosphat. Es war ursprünglich meine Absicht, auch die Keimpflanzen darauf zu untersuchen. Doch mußte ich aus äußeren Gründen meine Versuche abschließen. Anderenfalls würde ich auch noch eine größere Anzahl von Keimpflanzen untersucht haben.

\section{Bildung von Ammoniak bei der Autolyse von Keimpflanzen.}

Wenn man bei $35-40^{\circ}$ getrocknete und sodann zerriebene Keimpflanzen unter Zusatz von Wasser und eines Antiseptikums bei geeigneter Temperatur der Autolyse unterwirft, so findet bekanntlich infolge der Einwirkung der in den Keimpflanzen enthaltenen proteolytischen Enzyme auf die Eiweißsubstanzen eine Bildung von Monoaminosäuren und von Hexonbasen statt; diese Bildung unterbleibt, wenn man vor dem Versuch jenes Stoffgemisch auf $100^{\circ}$ erhitzt und dadurch die Enzyme unwirksam gemacht hat. Es war von Interesse, zu prüfen, ob während der Autolyse auch Ammoniakbildung stattfindet. Ich habe daher einige Versuche angestellt, für die ich ganz junge bei $35-40^{\circ}$ getrocknete Keimpflanzen von Lupinus luteus und Lupinus albus als Material verwendete. Das Versuchsverfahren war das gleiche wie bei den in unserem Laboratorium früher zur Ausführung gelangten Autolyseversuchen. In Glaskolben, die zuvor durch Erhitzen auf $130^{\circ}$ sterilisiert worden waren, brachte ich abgewogene Quantitäten des Keimpflanzenpulvers; auf je $1 \mathrm{~g}$ Trockensubstanz wurden $25 \mathrm{ccm}$ eines Gemisches von $20 \mathrm{ccm}$ Chloroform und $80 \mathrm{ccm}$ Wasser, sowie etwas Toluol zugesetzt. In jeder Versuchsreihe wurde ein Kolben vor Beginn der Autolyse auf $100^{\circ}$ erhitzt, um die Enzyme unwirksam zu machen, während dies bei den übrigen Kolben nicht geschah. Die Kolben wurden dann in den auf $35-40^{\circ}$ erwärmten Thermostaten gebracht und blieben darin 11-12 Tage; dann wurde der Ammoniakgehalt der im Kolben vorhandenen Flüssigkeit nach den im vorigen Abschnitt beschriebenen Methoden bestimmt. Aus der Differenz im Ammoniakgehalt der «gekochten" und der «nichtgekochten * Substanz ergibt sich, wieviel Ammoniak während der Autolyse sich ge- 
Uber das Vorkommen von Ammoniak in Keimpflanzen usw.

bildet hatte. Die Ergebnisse dieser Versuche sind in der nachfolgenden Tabelle zusammengestellt:

Ammoniakstickstoff in $100 \mathrm{~g}$ Trockensubstanz.

\begin{tabular}{|c|c|c|c|c|}
\hline & $\begin{array}{c}3-4 \text { tägige } \\
\text { Keimpflanzen } \\
\text { von Lupinus } \\
\text { luteus }\end{array}$ & $\begin{array}{c}\text { 4tägige } \\
\text { Keimpflanzen } \\
\text { von Lupinus } \\
\text { albus }\end{array}$ & $\begin{array}{c}7 \text { tảgige } \\
\text { Keimpflanzen } \\
\text { von Lupinus } \\
\text { albus }\end{array}$ & \\
\hline $\begin{array}{l}\text { Gekochte }^{1} \text { ) } \\
\text { Substanz }\end{array}$ & 0,0761 & 0,0744 & 0,0776 & $\begin{array}{l}\text { Direkt bei } \\
40^{\circ} \mathrm{C} \text {. in }\end{array}$ \\
\hline $\begin{array}{l}\text { Nicht gekochte } \\
\text { Substanz }\end{array}$ & $\begin{array}{l}0,2334 \\
0,2233\end{array}$ & $\begin{array}{l}0,2589 \\
0,2673\end{array}$ & $\begin{array}{l}0,2623 \\
0,2684\end{array}$ & Raum durch \\
\hline Mittelzahl & 0,2284 & 0,2621 & 0,2654 & abdestilliert. \\
\hline
\end{tabular}

Aus den in der Tabelle enthaltenen Zahlen geht hervor, daß die Autolyse der Keimpflanzen mit einer betrăchtlíchen Bildung von Ammoniak verbunden war. Was die Herkunft dieses Ammoniaks betrifft, so liegt es im Bereich der Möglichkeit, daß dasselbe bei der Spaltung der Eiweißsubstanzen durch die proteolytischen Enzyme neben Monoaminosäuren und Hexonbasen direkt gebildet worden war; aber es ist auch möglich, daß dieses Ammoniak erst beim Abbau primärer Eiweibzersetzungsprodukte sich gebildet hatte. Bei Diskussion dieser Frage ist auf einige schon vorliegende Untersuchungen hinzuweisen, zunächst auf die Arbeit von W. Butkewitsch") (Utber die Unwandlung der Eiweißstoffe durch die niederen Pilze und auf die Untersuchungen Shibatas. $\left.{ }^{8}\right)$ Dieser Forscher bespricht die Versuche von Butkewitseh und sagt, daß letzterer es unentschieden gelassen habe, ob die Ammoniakbildung in den Pilzen durch Oxydation oder auf enzymatischem Wege erfolgt

1) Was man unter agekochter und snicht gekochter» Substanz zu verstehen hat, ist aus den wie oben gemachten Darlegungen zu ersehen. \$. 47 .

2) Pringheims Jahrbücher für wissenschaftt. Botanik, Bd. XXXVIII,

8) Shibata, Über das Vorkommen von amidespaltenden Enzymen bei Pilzen, Beiträge z. chem. Physiologie u. Pathologie, Bd. V, S. 384-\$94. 
sei. Er hält das letztere für wahrscheinlich, hat jedoch die bezüglichen Enzyme nicht isoliert. Er schlägt vor, die Enzyme, welche diese Wirkung ausüben, als «Amidasen» zu bezeichnen; daß dieselben nicht mit den proteolytischen Enzymen identisch sind, geht nach seiner Ansicht aus den Versuchen von Gulewitsch ${ }^{1}$ ) und von Schwarzschild ${ }^{2}$ ) hervor. Ob die in verschiedenen Substanzen sich findenden Amidasen miteinander und mit der Urease identisch sind, bleibt unentschieden. Ferner ist auf Untersuchungen zu verweisen, die dem Gebiete der Tierphysiologie angehören, insbesondere auf die Abhandlung Jacobys: "Über die fermentative Eiweißspaltung und Ammoniakbildung in der Leber» ${ }^{3}$ ) und auf die Arbeit S. Langs ${ }^{4}$ ) "Über Desamidierung im Tierkörper». Auch sind hier noch die Arbeiten von Hirschler, ${ }^{5}$ ) Kutscher ${ }^{6}$ und Zuntz ${ }^{7}$ zu erwähnen.

Es ist also sehr wohl möglich, daß das bei der Autolyse der Keimpflanzen sich bildende Ammoniak wenigstens teilweise nicht primäres, sondern sekundäres Produkt des Eiweißabbaues ist. Mag das Ammoniak sich aber in der einen oder anderen Weise bilden, so ist es jedenfalls bemerkenswert, daß dasselbe in den lebenden Keimpflanzen sich nicht anhäuft; wie aus den von mir mitgeteilten Zahlen zu ersehen ist, enthalten etiolierte Keimpflanzen auch nach mehrwöchentlicher Dauer ihrer Vegetation nur eine geringe Ammoniakmenge. Dies führt zu der Schlußfolgerung, daß im Stoffwechsel der Keimpflanzen das Ammoniak verbraucht wird, und zwar ist es das Wahrscheinlichste, daß dasselbe bei der synthetischen Bildung von Asparagin und von Glutamin Verwendung findet. ${ }^{8}$ )

1) Diese Zeitschrift, Bd. XXVII, S. 540.

$\left.{ }^{2}\right)$ Beiträge zur chem. Physiologie u. Pathologie, Bd. IV, S. 155.

s) Diese Zeitschrift, Bd. XXX, S. 147.

4) Beiträge zur chem. Physiologie u. Pathologie, Bd. V, S. 321.

5) Diese Zeitschrift, Bd. X, S. 302.

$\left.{ }^{6}\right)$ Endprodukte der Trypsinverdauung, 1899.

7) Diese Zeitschrift, Bd. XXVIII, S. 132.

$\left.{ }^{8}\right)$ Ich verweise auf die Abhandlung von E. Schulze, Über den Abbau und den Auf bau organischer Stickstoffverbindungen in den Pflanzen, Landw. Jahrbücher, Bd. XXXV, S. 635. 
Über das Vorkommen von Ammoniak in Keimplanzen usw. 533

Analytische Belege.

\begin{tabular}{|c|c|c|c|c|c|c|}
\hline \multirow{2}{*}{$\begin{array}{c}\text { Namen } \\
\text { der } \\
\text { Keimpflanzen }\end{array}$} & \multirow{2}{*}{$\begin{array}{c}\text { Wasser- } \\
\text { gehalt } \\
\%\end{array}$} & \multirow{2}{*}{$\begin{array}{c}\text { Ange- } \\
\text { wendete } \\
\text { luft- } \\
\text { trockene } \\
\text { Substanz }\end{array}$} & \multicolumn{2}{|c|}{ Gefunden } & \multirow{2}{*}{$\begin{array}{l}\mathrm{N} \text { auf } \% \\
\text { Trocken- } \\
\text { substanz } \\
\text { berechnet }\end{array}$} & \multirow[b]{2}{*}{$\begin{array}{l}\text { Bemer- } \\
\text { kungen }\end{array}$} \\
\hline & & & $\begin{array}{c}\text { Natron- } \\
\text { lauge } \\
\text { ccm }\end{array}$ & $\begin{array}{l}\mathrm{N} \\
\mathrm{g}\end{array}$ & & \\
\hline $\begin{array}{c}\text { 3-4tägige } \\
\text { Keimpflanzen } \\
\text { vonLupinus } \\
\text { albus }\end{array}$ & $\begin{array}{l}11,52 \\
11,52 \\
11,52 \\
11,52\end{array}$ & $\begin{array}{l}4,0000 \\
4,0000 \\
4,0000 \\
4,0000\end{array}$ & $\begin{array}{l}0,93 \\
0,87 \\
0,95 \\
0,93\end{array}$ & $\begin{array}{l}0,0025761 \\
0,0024099 \\
0,0026315 \\
0,0025761\end{array}$ & $\begin{array}{l}0,0725 \\
0,0678 \\
0,0741 \\
0,0725\end{array}$ & $\cdot$ \\
\hline $\begin{array}{c}\text { 3-4 tägige } \\
\text { Keimpflanzen } \\
\text { von Lupinus } \\
\text { luteus }\end{array}$ & $\begin{array}{l}9,00 \\
9,00 \\
9,00\end{array}$ & $\begin{array}{l}3,0000 \\
3,0000 \\
3,0000\end{array}$ & $\begin{array}{l}0,75 \\
0,72 \\
0,70\end{array}$ & $\mid \begin{array}{l}0,0020775 \\
0,0019944 \\
0,001939\end{array}$ & $\begin{array}{l}0,07609 \\
0,07304 \\
0,07102\end{array}$ & \\
\hline $\begin{array}{l}\text { 7tägige Keim- } \\
\text { pflanzen von } \\
\text { Lupinus albus }\end{array}$ & $\begin{array}{l}10,22 \\
10,22\end{array}$ & $\begin{array}{l}2,0000 \\
2,0000\end{array}$ & $\begin{array}{l}0,48 \\
0,50\end{array}$ & $\begin{array}{l}0,0013296 \\
0,001385\end{array}$ & $\begin{array}{l}0,0747 \\
0,0776\end{array}$ & \\
\hline $\begin{array}{l}\text { 9-10tägige } \\
\text { frische Keim- } \\
\text { pflanzen von } \\
\text { Lupinus albus }\end{array}$ & $\begin{array}{l}7,25 \\
7,25\end{array}$ & $\begin{array}{l}8,7687 \\
8,7687\end{array}$ & $\begin{array}{l}2,25 \\
2,30\end{array}$ & $\begin{array}{l}0,0062325 \\
0,006371\end{array}$ & $\begin{array}{l}0,07623 \\
0,07792\end{array}$ & $\begin{array}{l}1 \text { ccm } \\
\text { Natron- } \\
\text { lauge }\end{array}$ \\
\hline $\begin{array}{l}11-12 \text { tăgige } \\
\text { Keimpflanzen } \\
\text { von Lupinus } \\
\text { albus }\end{array}$ & $\begin{array}{l}7,70 \\
7,70\end{array}$ & $\begin{array}{l}3,7911 \\
3,0102\end{array}$ & $\begin{array}{l}1,80 \\
1,50\end{array}$ & $\begin{array}{l}0,004986 \\
0,00416\end{array}$ & $\begin{array}{l}0,1000 \\
0,1310\end{array}$ & $\begin{array}{c}0,00277 \mathrm{~g} \\
\mathrm{~N}\end{array}$ \\
\hline $\begin{array}{c}12 \text { tägige } \\
\text { Erbsen- } \\
\text { keimpflanzen }\end{array}$ & 8,20 & $\begin{array}{l}5,4100 \\
5,4100\end{array}$ & $\begin{array}{l}2,00 \\
2,05\end{array}$ & $\begin{array}{l}0,00554 \\
0,0056785\end{array}$ & $\begin{array}{l}0,1108 \\
0,1135\end{array}$ & \\
\hline $\begin{array}{c}7 \text { tägige } \\
\text { frischeKürbis- } \\
\text { keimlinge }\end{array}$ & $\begin{array}{l}8.98 \\
8,98\end{array}$ & $\begin{array}{l}5,3121 \\
5,3121\end{array}$ & $\begin{array}{l}1,80 \\
1,85\end{array}$ & $\begin{array}{l}0,004986 \\
0,0051245\end{array}$ & $\begin{array}{l}0,1022 \\
0,1051\end{array}$ & \\
\hline $\begin{array}{c}20 \text { tägige } \\
\text { Keimpflanzen } \\
\text { von Lupinus } \\
\text { albus }\end{array}$ & $\begin{array}{l}12,63 \\
12,63\end{array}$ & $\begin{array}{l}10,0000 \\
10,0000\end{array}$ & $\begin{array}{l}3,33 \\
3,66\end{array}$ & $\begin{array}{l}0,009233 \\
0,01014\end{array}$ & $\begin{array}{l}0,1056 \\
0,1159\end{array}$ & \\
\hline
\end{tabular}



N. Gastoro, Über das Vorkommen von Ammoniak.

Autolyse-Versuche.

\begin{tabular}{|c|c|c|c|c|c|c|}
\hline \multirow{2}{*}{$\begin{array}{c}\text { Namen } \\
\text { der } \\
\text { Keimpflanzen }\end{array}$} & \multirow{2}{*}{$\begin{array}{c}\text { Wasser- } \\
\text { gehalt } \\
\%\end{array}$} & \multirow{2}{*}{$\begin{array}{c}\text { Ange- } \\
\text { wendete } \\
\text { luft- } \\
\text { trockene } \\
\text { Substanz }\end{array}$} & \multicolumn{2}{|c|}{ Gefunden } & \multirow{2}{*}{$\begin{array}{l}\mathrm{N} \text { auf } \% \\
\text { Trocken- } \\
\text { substanz } \\
\text { berechnet }\end{array}$} & \multirow[b]{2}{*}{$\begin{array}{l}\text { Bemer- } \\
\text { kungen }\end{array}$} \\
\hline & & & $\begin{array}{c}\text { Natron- } \\
\text { lauge } \\
\%\end{array}$ & $\begin{array}{l}\mathrm{N} \\
\mathrm{g}\end{array}$ & & \\
\hline $\begin{array}{c}\text { 3-4tägige } \\
\text { gelbeLupinen } \\
\text { Gekochte } \\
\text { Substanz }\end{array}$ & 9,00 & 3,0000 & 0,75 & 0,0020775 & 0,0761 & \\
\hline $\begin{array}{c}\text { Nicht } \\
\text { gekochte } \\
\text { Substanz }\end{array}$ & $\begin{array}{l}9,00 \\
9,00\end{array}$ & $\begin{array}{l}3,0000 \\
3,0000\end{array}$ & $\begin{array}{l}2,30 \\
2,20\end{array}$ & $\begin{array}{l}0,006371 \\
0,006094\end{array}$ & $\begin{array}{l}0,2334 \\
0,2233\end{array}$ & \\
\hline $\begin{array}{c}\text { 4tägige weiße } \\
\text { Lupinen } \\
\text { Gekochte } \\
\text { Substanz }\end{array}$ & 10,71 & 2,0000 & 0,48 & 0,0013296 & 0,0744 & $\begin{array}{l}1 \mathrm{ccm} \\
\text { Natron- } \\
\text { lauge }\end{array}$ \\
\hline $\begin{array}{c}\text { Nicht } \\
\text { gekochte } \\
\text { Substanz }\end{array}$ & $\begin{array}{l}10,71 \\
10,71\end{array}$ & $\begin{array}{l}2,0000 \\
2,0000\end{array}$ & $\begin{array}{l}1,67 \\
1,72\end{array}$ & $\begin{array}{l}0,004625 \\
0,0047644\end{array}$ & $\begin{array}{l}0,2589 \\
0,2673\end{array}$ & $\begin{array}{c}= \\
0,00277 \mathrm{~g}\end{array}$ \\
\hline $\begin{array}{c}\text { 7tägige weiße } \\
\text { Lupinen } \\
\text { Gekochte } \\
\text { Substanz }\end{array}$ & 10,22 & 2,0000 & 0,50 & 0,001385 & 0,0776 & \\
\hline $\begin{array}{c}\text { Nicht } \\
\text { gekochte } \\
\text { Substanz }\end{array}$ & $\begin{array}{l}10,22 \\
10,22\end{array}$ & $\begin{array}{l}2,0000 \\
2,0000\end{array}$ & $\begin{array}{l}1,70 \\
1,73\end{array}$ & $\begin{array}{l}0,004709 \\
0,0048198\end{array}$ & $\begin{array}{l}0,2623 \\
0,2684\end{array}$ & \\
\hline
\end{tabular}

